\title{
Apology in Japanese Business Communication: Its Functions and Impacts in the Eyes of Japanese "Salarymen"
}

\section{Seoh Koon Tan}

\author{
Josai University, Saitama, Japan
}

Objectives: This research investigated various workplace scenarios of Japanese apologies, aiming to observe the following aspects of apology: (1) What purpose does apology serve in the Japanese business setting; (2) What influences the Japanese office workers in using certain form of apology; (3) What determines the effectiveness of apology.

Methods: Semi-structured phone interviews were carried out with 33 Japanese office workers to collect relevant data. All the phone interviews were recorded and analyzed using qualitative content analysis.

Results: Results indicated that the main purposes of apology in Japanese business setting include "to be polite," "to seek forgiveness," "to forge ties," "to take responsibility," "to rebuild trust," and "to show gratitude and indebtedness." The forms of apology used by Japanese office workers were strongly influenced by Japanese cultures, which include Honne to Tatemae, Kenkyo, and Shudan Ishiki. Results showed that factors for an effective apology in Japanese business setting include sunao, severity of the offense, existence of preceding offense, interpersonal relationships, and power distance.

Conclusions: In the Japanese business setting, the purposes of apology, form of apology, and effectiveness of apology were influenced by several linguistic, social, and cultural factors.

Key Words: Apology, Business Communication, Japanese Culture, Functions of Apology, Effectiveness of Apology

\section{Introduction}

Being polite is desirable in all cultures, and Japanese culture is particularly well-known for placing a high value on being

Received: Apr 5, 2019 Revised: Apr 29, 2019 Accepted: May 1, 2019 Corresponding author: Seoh Koon TAN

Josai University, Keyakidai, Sakado-shi, Saitama-ken 350-0295, Japan Tel: +81-49-271-7663, E-mail: tansk@josai.ac.jp

This is an Open Access article distributed under the terms of the Creative Commons Attribution Non-Commercial License (http://creativecommons.org/licenses/ by-nc/4.0/) which permits unrestricted non-commercial use, distribution, and reproduction in any medium, provided the original work is properly cited.

Copyright $(9) 2019$ Korean Association for Business Communication. courteous. Being a culture that places heavy emphasis on politeness and mindfulness, the apology etiquette is observed carefully and strictly in Japan. There are many phrases that can be used to apologize in the Japanese language, depending on the level of formality. Phrases such as moushiwake arimasen, taihen moushiwake gozaimasen, and shitsurei itashimasu, which mean "I am sorry," or taihen gomeiwaku o kakete moushiwake gozaimasendeshita, which means "I am very sorry for the trouble," are widely used in more formal settings. As for more casual situations, phrases such as gomen, gomen nasai, and sumimasen, which mean "sorry," or warui warui, which means "my bad," are regularly used.

Among all these Japanese terms used to express apology, 
sumimasen is considered the most well-known word that even most foreigners who do not speak Japanese know. According to many scholars (Coulmas , 1981; Ide , 1998; Kindaichi , 1987), sumimasen is an apology expression, which can also be used alongside gratitude expressions in Japanese (as cited in Long, 2010). However, to many foreigners who have limited knowledge of Japanese language, sumimasen simply means "sorry," as they only cling to one meaning of the word, regardless of the context. This explains why "Japanese are apologetic" has become a very common Japanese stereotype.

Being a foreigner working and living in Japan, I was often asked by people from different cultures "Why do Japanese people apologize so much?" Some have even commented that Japanese apology is unnecessary self-effacement. But, can the frequency in using one lexical item sumimasen be simply generalized as "Well, Japanese are polite" or "You know, Japanese are apologetic"? I believed that there must be something behind Japanese's apology culture that is worth looking into. It was with such belief in mind that this study was conducted.

Apology was defined as "a fundamental speech act which is a part of human communication occurs in every culture to maintain good relations between interlocutors" (Halimeh, Habib, \& Akbar, 2015, p. 205). Although apology is a ubiquitous act across cultures, disparities in purposes, forms, and strategies of apology are expected in different cultures as culture is a strong influence on social behaviors. Failure in observing and conforming to the social rules of apology in one culture might make someone be seen as communicatively incompetent (Guan, Park, \& Lee, 2009), which might cause serious damage to interpersonal relationships. Knowing such disparities are thus important in promoting successful cross-cultural communication.

This study aimed to provide practical insights in the following aspects of apology: (1) What purpose does apology serve in the Japanese business setting; (2) What influences the Japanese office workers in using a certain form of apology; (3) What determines the effectiveness of an apology.

\section{Methods}

\section{Participants}

A total of 33 Japanese office workers (22 males; 11 females), ages ranging from 27 to 49 years old (mean age: 36.95), were recruited online on a voluntary basis using HelloTalk. HelloTalk is a language exchange learning application that can be downloaded for free by all Android and iOS users. The main reason for HelloTalk being selected to recruit participants was that there were more potential volunteers from this platform because users were mainly language learners who were keen to com- municate with foreigners, and most of them treated the phone interview sessions as a chance to have a language exchange with people from other culture. With a free account, users can post messages that can be viewed and responded to by all the other users. This function was used to recruit volunteers to participate in the phone interviews. The application also allowed users to send text messages, voice messages, and make voice calls. These functions were helpful in the data collection process.

\section{Data Collection}

Semi-structured phone interviews were carried out in both English and Japanese. During the interviews, participants were asked to recall and share occurrences when they had to apologize at the workplace by answering the following interview questions:

(1) What are some common phrases that Japanese people use to apologize at the workplace?

(2) Could you recall any specific incidents that you have used “__ " (phrases for apologizing, such as sumimasen) to apologize? Explain what happened.

(3) Explain in detail what you said and did at that time.

There was no limit as to the number of occurrences that could be shared by a single participant. To help interviewees focus on the details of the important concrete occurrences they shared and what the outcomes were, the following "WH-probes" were used:

- What happened next?

- Why did it happen?

- How did it happen?

- Why did you do that?

- What were the consequences?

- Was it effective? Why or why not?

To collect more useful data, participants were also asked to comment and react to researcher-created situations, which included but were not limited to the following situations:

- You have sent the wrong items to your client and he is now very angry.

- You heard that your colleagues were very busy handling some customers when you stepped out.

- You have made a mistake that caused financial loss to your company.

With the consent of participants, all the phone interviews were recorded and analyzed using qualitative content analysis. During the coding process, it was decided that texts related to or being considered as an apology would be coded based on 
based on the following definition of apology - verbal or nonverbal behavior (1) involving at least one lexical item directly signaling apology (such as sorry), or (2) expressing regret and responsibility even though lexical items associated with apology are not included (such as bowing). Once the relevant texts were coded, repeating ideas were identified to form different themes.

\section{Results}

There was a total of 131 occurrences ( 78 cases shared by participants; 53 cases researcher created situations) being coded and analyzed to answer the three research questions (RQs).

\section{R01: What Purpose Does Apology Serve?}

Table 1 summarized the purposes of apology in a Japanese business context. In a total of 131 occurrences, respondents related the occurrences to their specific purposes of apology, and some respondents related certain occurrences to multiple purposes.

Consider the following conversation during the phone interview (Excerpt 1). Based on the Excerpt 1, three different purposes - to seek forgiveness, to take responsibility, and to rebuild trust were coded in one specific occurrence shared by the respondent.

As shown in Table 1, respondents associated the occurrences of "to seek forgiveness" only 63 times. And interestingly, in these 63 cases, 20 cases involved indirect responsibility in which the apologizers apologized for offenses committed by others. Consider the following excerpt from the phone interview (Excerpt 2).

Table 1. Purposes of apology in Japanese business context

\begin{tabular}{clc}
\hline No & \multicolumn{1}{c}{ Purpose } & Frequency \\
\hline 1 & To be polite & 98 \\
2 & To seek forgiveness & 63 \\
3 & To forge ties & 36 \\
4 & To take responsibility & 30 \\
5 & To rebuild trust & 20 \\
6 & To show gratitude and indebtedness & 16 \\
\hline
\end{tabular}

R02: What Influences the Japanese Office Workers in using a Certain Form of Apology?

Excerpt 3 is the exact apology (translated from Japanese to English) used by one of our participants when apologizing to a customer. During the phone interview, respondents were asked to recall what they said when they apologized in the situations they shared.

Analysis of the apologies used by the participants of the study showed the following common characteristics:

- Describe the offense or damage as more severe than the offender thinks

- Humble (use of honorific form) and beg for forgiveness to a greater extent

- Criticize oneself

- Emphasize on negative aspects

- Promise to repair and not to repeat the same offense

- The use of formulaic expressions

What influences them in using such form of apology? Two related and interesting characteristics worth looking into are describing the offense or damage as more severe than the offender thinks it actually is and criticizing oneself. Data showed that phrases that are only being used when apologizing, such as "sorry for causing serious inconvenience," "sorry for my lack of virtue," "deeply reflecting upon our mistake," and "please forgive my rudeness" are usually very strong words to show that the offender deeply regretted on his/her failure (Excerpt 4). Casual apologizing words are considered "insufficient."

\section{R03: What Determines the Effectiveness of Apology?}

Table 2 summarizes the results related to factors for an effective apology. It is important to note that only genuine apologies, which are apologies to seek forgiveness, were taken into consideration when analyzing the data for the effectiveness of an apology. Among all the factors, sunao was the factor most frequently mentioned by the respondents, as illustrated in Excerpt 5 .

Excerpt 1. Three different purposes of apology

\begin{tabular}{|c|c|}
\hline Researcher & : Why did you say "moushiwake gozaimensen"? \\
\hline Respondent & $\begin{array}{l}\text { Because the customer was angry. My colleague who was in charge of the case } \\
\text { was not in the office so I had no choice but to apologize. It is our company's } \\
\text { responsibility. I wanted the customer to forgive us. }\end{array}$ \\
\hline Researcher & : Hmm... I see. And you... \\
\hline Respondent & $\begin{array}{l}\text { : Because our relationship with the customer is important. If we had not } \\
\text { apologize sincerely, the customer would have thought that the company was } \\
\text { unreliable. }\end{array}$ \\
\hline
\end{tabular}


Excerpt 2. Apology involving indirect responsibility

$$
\begin{aligned}
& \text { Researcher } \quad \text { What happened after that? } \\
& \text { Respondent } \quad \text { I had to apologize. } \\
& \text { Researcher } \quad \text { But you said that you were not the one who took care of those goods in the } \\
& \text { warehouse? } \\
& \text { Respondent } \quad \text { It's everybody's responsibility. Everyone in the department bears the } \\
& \text { responsibility. }
\end{aligned}
$$

\begin{tabular}{|c|c|}
\hline Researcher & : Lack of virtue... These words were really strong. \\
\hline Respondent & $\begin{array}{l}\text { Japanese expressions are sometimes a little exaggerated. But at the workplace, } \\
\text { if you only use "sumimasen" to apologize, it sounds like you are taking things } \\
\text { too lightly. So, you have to use terms only used for apologies. }\end{array}$ \\
\hline Researcher & :What if it is just a very small matter? \\
\hline Respondent & $\begin{array}{l}\text { It doesn't really matter how big or how small the mistake is; we still say "sorry } \\
\text { for causing you so much trouble." }\end{array}$ \\
\hline
\end{tabular}

\section{Excerpt 3. Apology used when apologizing to a customer}

"This issue occurred due to our lack of confirmation, and we are deeply reflecting upon our failure. In the future, we will improve our checking system and work with utmost care to prevent such trouble. Please accept my humble apology."

Excerpt 4. Strong versus casual apology words

Table 2. Factors for effective apology

\begin{tabular}{clc}
\hline No & \multicolumn{1}{c}{ Factor } & Frequency \\
\hline 1 & Sunao & 19 \\
2 & Severity of the offense & 15 \\
3 & Existence of preceding offense & 13 \\
4 & Interpersonal relationship & 5 \\
5 & Power distance & 4 \\
\hline
\end{tabular}

\section{Discussion}

\section{Purpose of Apology}

Interestingly, based on the results, the frequency of using apology expressions for other purposes (to show politeness, to establish good relationship, to show gratitude, etc.) was much higher than using them for a genuine apology (apology to seek forgiveness after an offence) in the Japanese business setting. As discussed earlier, apology expressions in Japanese, such as sumimasen, can also be used as gratitude expressions (Long, 2010), better known as "apology-gratitude expressions" (Oki , 1993 as cited in Long, 2010). As a society that places heavy emphasis on courtesy, the concept of politeness in the Japanese culture is beyond just being well-mannered. Being polite also means mei- waku o kakenai or "not-to-bother-others." Apology-gratitude expressions are used to express recognition of a burden suffered by the hearer (Long, 2010, p. 1061). Upholding such a course of conduct, even the smallest favor in Japan is seen as an action that brings inconvenience or trouble to others, resulting in a feeling of guilt. This culture of indebtedness as the central concept of politeness in Japanese culture explains the commonly used apology-gratitude expressions in Japanese society. Besides, based on the Japanese culture of kenkyo, which means the virtue of modesty, lowering oneself when interacting with others is seen as a virtue that is highly valued and encouraged (Roger \& Ikeno, 2002). This is shown in the complicated honorific system of Japanese language - the polite speech (teineigo), the honorific speech (sonkeigo), and the humble speech (kenjogo). Linguistically, apology-gratitude sounds less arrogant and it serves the function of lowering oneself when showing gratitude.

Unlike other cultures, Japanese are expected not only to apologize for their own mistakes, but often also to apologize for offenses committed by others, as illustrated in Excerpt 2. This can be explained by the Japanese culture of Uchi and Soto. Uchi means inside or the group that I belong to and soto, on the other hand, means outside, other groups (that I do not belong to; Hendry, 2013). Based on this culture, the group of people 
Excerpt 5. Factors influencing effectiveness of apology

"When it is our own fault, immediately apologize in a sunao manner is important."

"I think attitude and the level of sunao is important."

that Japanese consider having close responsibility to (uchi) encompasses a large part of their social network compared to other cultures because the group that I belong to might include friends, collogues, customers. This explains why Japanese people naturally encounter more occurrences that require an apology (Sugimoto, 1998), which is why others may have the impression that Japanese people are more apologetic. Other than that, Japanese's Shudan Ishiki also has its influence on the social practice of apology. Shudan Ishiki can be translated as group consciousness. In Japanese society, people are primarily group-oriented and give more priority to group harmony than individuality (Roger \& Ikeno, 2002). Loyalty to the group produces a feeling of solidarity. Therefore, it is not difficult to understand why Japanese people have a much larger $u c h i$ social network compared to other cultures and take responsibility for actions done by members in their uchi circle.

\section{Factors Influencing the Use of a Certain Form of Apology}

The form of apology used by Japanese is influenced by the Japanese concepts of Honne and Tatemae. According to Matsumoto (1988), honne means genuine feeling or intention, whereas tatemae means feeling or intention that is tuned in accordance to social norms or the socially controlled opinion. It is seen as a virtue in Japanese society for not expressing one's honne directly, and tatemae is used as a lubricating oil to maintain harmony (Roger \& Ikeno, 2002). Thus, describing the offense as more severe and to criticize oneself are considered virtues that describe the offense closer to the victim's perception.

Furthermore, as explained earlier, kenkyo, or the virtue of modesty, also explained why the forms of apology used by Japanese office workers were exceptionally humble and begged for forgiveness to a greater extent. As illustrated by the famous Japanese saying, "Rice plant's ears grow ripe and hang low," Japanese are expected to be humble and polite, regardless of social position (Roger \& Ikeno, 2002).

Finally, it is also interesting to note the use of formulaic expressions as one of the characteristics of apology in the Japanese business setting. Significantly influenced by the Japanese concept of shudan ishiki, or group consciousness, Japanese often think and behave in accordance to their norms. Unlike many other cultures, creativity is not emphasized in certain situations compared to the importance of adhering to norms, as demonstrated in the famous Japanese saying, "The nail that sticks up gets hammered down." This is a powerful force that make Japanese people adhere to formulas, and it explains why formulaic expressions are commonly used. Goldstein and Tamura (1975) emphasized that the use of formulaic expressions should not be mistaken as Japanese people having rigid interpersonal communication. In fact, Japanese speakers can easily retain the honorific forms and yet make usage quite informal. According to Sugimoto (1998), the use of a formulaic apology does not make an apology sound less sincere because the pursuit of heart and form are different matters and could be accomplished simultaneously in a Japanese apology. This might be rather different in other cultures.

\section{Effectiveness of Apology}

According to Sugimoto (1998), sunao seems to best reflect the cultural ideal for Japanese apology. Being sunao cannot be translated as being "sincere," as these two words are not identical concepts. Being sincere, in many cultures, means to be wholehearted or based on physical truthfulness, whereas being sunao in the Japanese context, according to Wagatsuma and Rosett (1986), focuses more on relational truthfulness and the attainable externality of submission to order and return to harmonious relationship. Therefore, as discussed earlier, to describe an offense as more severe and closer or true to the victim's perception of the situation (the relational truthfulness) is the essence of being sunao, which is different from being sincere in other cultures.

Other than that, it is also worth mentioning that four respondents suggested that the more social power the offender has, the higher likelihood is of his/her apology being accepted by the victim. Respondents shared that they felt obliged and inferior to offenders who are their senpai, people who are more experienced in the company. Nakane (1995) described Japan as a vertical society that emphasize superior-subordinate relationships. This has a strong influence on human relationship in the business world. Such consciousness might cause a sense of inferiority among kohai, people who are less experienced, and thus make an apology from a senpai more likely to be accepted.

On the other hand, there were limitations in this study that should be considered for future research. First of all, the findings might only be applicable to a narrow context. Further studies focusing on other settings are necessary to provide more valuable insights in this field. Future studies with a bigger sam- 
ple size should also be conducted to look into this issue more deeply.

\section{Conclusion}

In conclusion, this study highlighted the complex art of apology in Japanese culture. Culture plays an important role in influencing factors, forms, and effectiveness of an apology in Japanese society alongside other linguistic and social factors. Apologies serve the following purposes at workplace in the Japanese business context: to be polite, to seek forgiveness, to forge ties, to take responsibilities, to rebuild trust, and to show appreciation and indebtedness. The forms of apology were influenced by several cultural factors: modesty, genuine vs social-controlled feelings, and group consciousness, and the effectiveness of apologies were moderated by the perceived sunao, the severity of the offense, the existence of preceding offenses, the interpersonal relationships of the parties involved, and power distance.

\section{References}

Goldstein, B. Z., \& Tamura, K. (1975). Japan and America: A com- parative study of language and culture. Tokyo, Japan: Tuttle.

Guan, X., Park, H. S., \& Lee, H. E. (2009). Cross-cultural differences in apology. International Journal of Intercultural Relations, 33(1), 32-45.

Halimeh, G., Habib, G., \& Akbar, A. (2015). Investigating apology strategy among Kurdish bilinguals: A case study in Ilam. Procedia - Social and Behavioral Sciences, 199, 204-210.

Hendry, J. (2013). Understanding Japanese society (4th ed.). Oxon, UK: Routledge.

Long, C. (2010). Apology in Japanese gratitude situations: The negotiation of interlocutor role-relations. Journal of Pragmatics, 42(4), 1060-1075.

Matsumoto, M. (1988). The unspoken way - Haragei: Silence in Japanese business and society. New York, NY: Kodansha.

Nakane, C. (1995). Japanese society. Tokyo, Japan: Tuttle.

Roger, J. D., \& Ikeno, O. (Eds.). (2002). The Japanese mind: Understanding contemporary Japanese culture. Tokyo, Japan: Tuttle.

Sugimoto, N. (1998). Norms of apology depicted in U.S. American and Japanese literature on manners and etiquette. International Journal of Intercultural Relations, 22(3), 251-276.

Wagatsuma, H., \& Rosett, A. (1986). The implications of apology: Law and culture in Japan and the United States. Law and Society Review, 20(4), 461-498. 